July 2015 at the burns unit in our centre. Of 25 patients, 15 were male and 10 female, with median age of 2 years. These 25 patients included 20 scalds, 4 flame burns and 1 electric burn. The mean percentage of total burn surface area was $27.5 \%$.

The bed pad used as dressing material has three layers:

a. Inner layer is a non-woven cotton layer which ensures maximum dispersion of the absorbed liquid and increased core strength

b. Intermediate absorbent layer of long virgin pulp fibres for maximum absorbency

c. Outer layer is a polyethylene backing with sealed edges which is water impermeable. A single bed pad measures $60 \mathrm{~cm} \times 90 \mathrm{~cm}$ in dimension and costs around Rs. 110.

All the patients were dressed in an operation theatre with all sterile precautions. A new sterile pack of bed pad was used in each patient. It was cut so that it would conform to the shape and size of the wound. A layer of $1 \%$ silver sulphadiazine was then generously smeared on the absorbent inner surface of cut pieces. Once the wound cleaning was done with running water, the smeared bed pad with $1 \%$ silver sulphadiazine side on the wound was applied in a way that the ends overlapped, so that the entire burn wound was covered. The bed pad was then fastened with a cotton roller bandage to

Bed pad as an alternative painless, comfortable and economical burn wound dressing

Sir,

We put forth our experience in the use of bed pads as an alternative burn wound dressing. Bed pads are widely used in hospitals to prevent the bed soiling with urine. ${ }^{[1]}$ They have excellent fluid absorption capacity hence are used frequently for bed protection in case of urinary incontinence, paediatric wards and in obstetric clinics.

Bed pads have been used as dressing material for burn wounds at our centre for the last 10 years. ${ }^{[2]}$ Role of this dressing was observed in 25 patients from August 2014 to retain it in place over which an elastic crepe bandage was applied [Figures 1 and 2].

Parents of 22 patients found that the patients were comfortable and less irritable after the dressing; the remaining 3 patients had come to our centre at an average of 2 days post-burn with full thickness burns

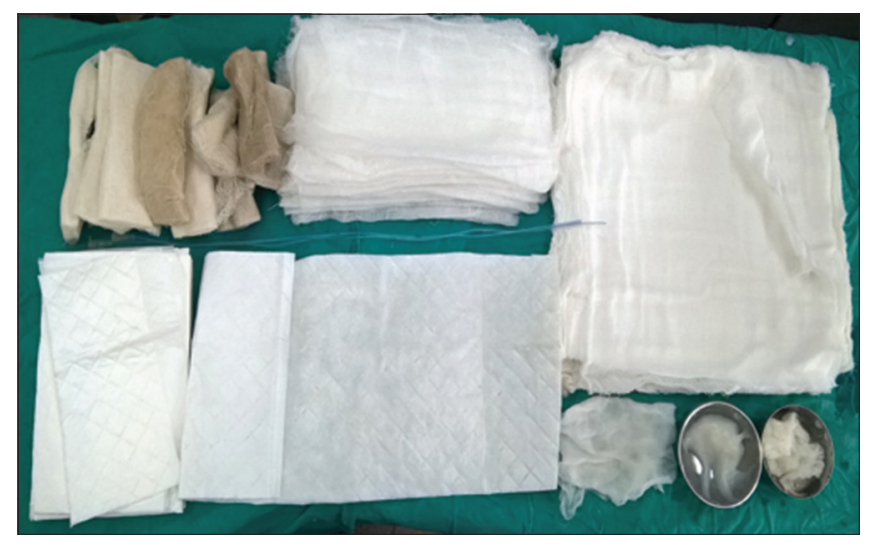

Figure 1: Dressing trolley 


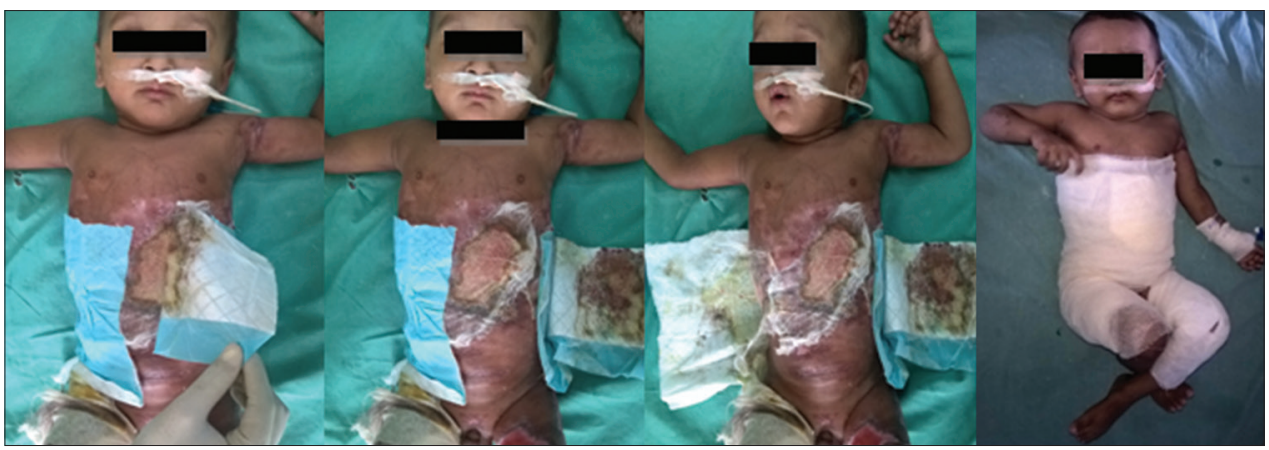

Figure 2: Painless removal of bed pad dressing
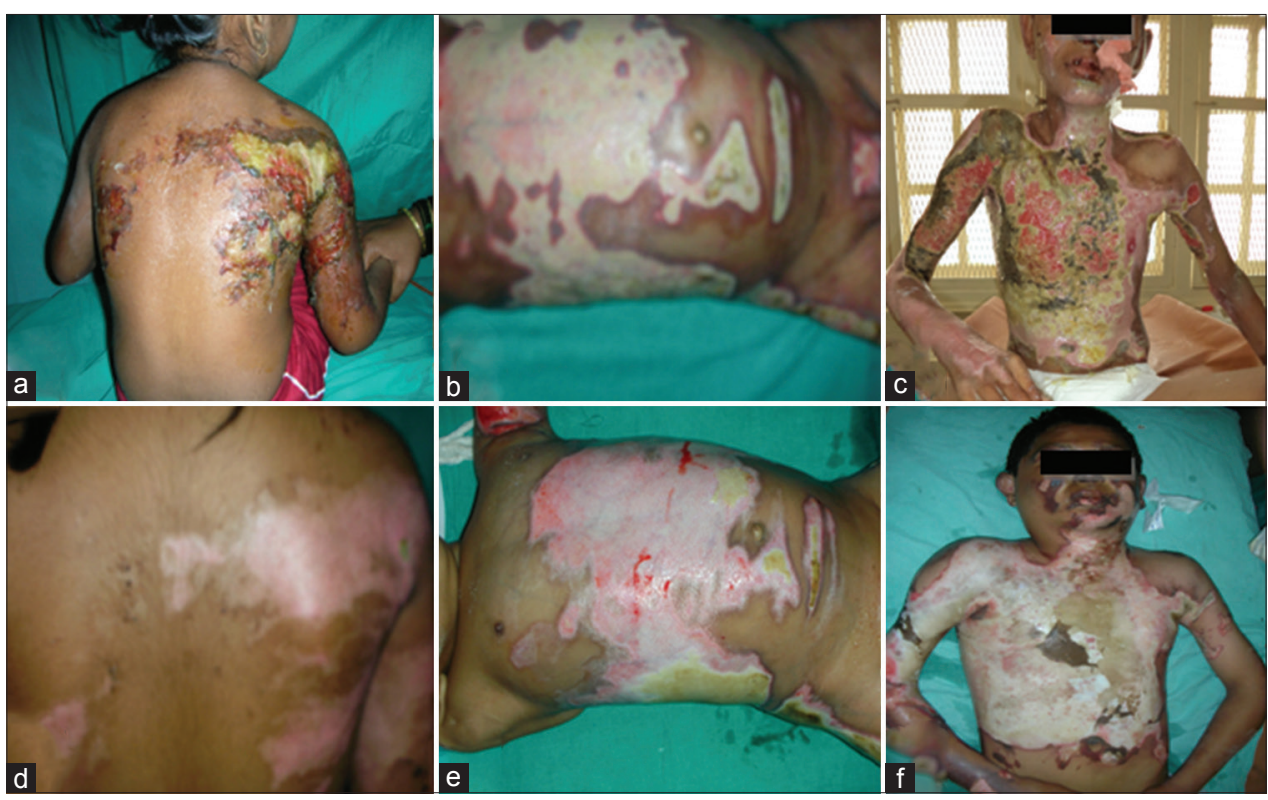

Figure 3: (a-c) Pre dressing photos of the patient of burns. (d-f) Post dressing photos of the patient

and hence were irritable initially but found improved on subsequent dressings. As it was non-adherent to the wounds, the removal of dressing was found to be painless in all 25 patients [Figure 2]. Out of the 25 patients, 15 patients with superficial and partial thickness burns healed spontaneously with bed pad and $1 \%$ silver sulphadiazine in a mean of 8.5 days (range 7-10 days) and 17.5 days (15-20 days), respectively. The remainder who had full thickness burn wounds required split-thickness skin grafts [Figure 3].

Thus, we can safely conclude that bed pads can be used in burn wounds as a cheap alternative to composite synthetic dressing material ${ }^{[3]}$ in our country and has easy application which is quite painless due to retention of moisture and need to be changed once a day. We strongly recommend its use; however, further controlled clinical, histological and bacteriological studies of the burn wounds are required for its evaluation.

\section{Declaration of patient consent}

The authors certify that they have obtained all appropriate patient consent forms. In the form the patient(s) has/have given his/her/their consent for his/her/their images and other clinical information to be reported in the journal. The patients understand that their names and initials will not be published and due efforts will be made to conceal their identity, but anonymity cannot be guaranteed.

\section{Financial support and sponsorship} Nil.

\section{Conflicts of interest}

There are no conflicts of interest.

Kirti Garude, Shankar Srinivasan, Nikunj Bhavesh Mody, Bipin Ghanghurde, Jovita Saldanha, Arvind Vartak, Suhas Abhyankar 
Department of Burns and Plastic Surgery, B.J. Wadia Hospital for Children, Mumbai, Maharashtra, India

Address for correspondence: Dr. Shankar Srinivasan, Burns Research Unit, B.J. Wadia Hospital, Acharya Donde Marg, Lower Parel, Mumbai - 400 012, Maharashtra, India. E-mail: wadiaburnsandplastic@gmail.com

\section{REFERENCES}

1. Cottenden AM, Dean GE, Brooks RJ, Haines-Nutt RF, Rothwell JG, Penfold $\mathrm{PH}$, et al. Disposable bedpads for incontinence: Predicting their clinical leakage properties using laboratory tests. Med Eng Phys 1998;20:347-59.

2. Verma SS, Srinivasan S, Vartak AM. An epidemiological study of 500 paediatric burn patients in Mumbai, India. Indian J Plast Surg 2007;40:153-7.

3. Laurie S. Wound Dressing Selection: Types and Usage; 2011. Available from: http://www.woundsource.com/product-category/ dressings. [Last accessed on 2017 Sep 25].

This is an open access article distributed under the terms of the Creative Commons Attribution-NonCommercial-ShareAlike 3.0 License, which allows others to remix, tweak, and build upon the work non-commercially, as long as the author is credited and the new creations are licensed under the identical terms.

\begin{tabular}{|l|l|}
\hline \multicolumn{2}{|c|}{ Access this article online } \\
\hline Quick Response Code: & Website: \\
\hline & www.ijps.org \\
\cline { 2 - 2 } & \\
\hline
\end{tabular}

How to cite this article: Garude $\mathrm{K}$, Srinivasan $\mathrm{S}$, Mody NB, Ghanghurde B, Saldanha J, VartakA, et al. Bed pad as an alternative painless, comfortable and economical burn wound dressing. Indian J Plast Surg 2017;50:317-9.

๑ 2017 Indian Journal of Plastic Surgery | Published by Wolters Kluwer - Medknow 